\title{
Higher brain extracellular potassium is associated with brain metabolic distress and poor outcome after aneurysmal subarachnoid hemorrhage
}

Ana Patrícia Antunes ${ }^{1,2 \dagger}$, Alois Josef Schiefecker ${ }^{1 \dagger}$, Ronny Beer ${ }^{1}$, Bettina Pfausler ${ }^{1}$, Florian Sohm ${ }^{3}$, Marlene Fischer ${ }^{1}$, Anelia Dietmann ${ }^{1}$, Peter Lackner ${ }^{1}$, Werner Oskar Hackl${ }^{4}$, Jean-Pierre Ndayisaba', Claudius Thomé3,

Erich Schmutzhard ${ }^{1}$ and Raimund Helbok ${ }^{* *}$

\begin{abstract}
Introduction: Elevated brain potassium levels $\left(\left[\mathrm{K}^{+}\right]\right)$are associated with neuronal damage in experimental models. The role of brain extracellular $\left[\mathrm{K}^{+}\right]$in patients with poor-grade aneurysmal subarachnoid hemorrhage (aSAH) and its association with hemorrhage load, metabolic dysfunction and outcome has not been studied so far.

Methods: Cerebral microdialysis (CMD) samples from 28 poor grade aSAH patients were analyzed for CMD $\left[\mathrm{K}^{+}\right]$ for 12 consecutive days after ictus, and time-matched to brain metabolic and hemodynamic parameters as well as corresponding plasma $\left[\mathrm{K}^{+}\right]$. Statistical analysis was performed using a generalized estimating equation with an autoregressive function to handle repeated observations of an individual patient.
\end{abstract}

Results: $\mathrm{CMD}\left[\mathrm{K}^{+}\right]$did not correlate with plasma $\left[\mathrm{K}^{+}\right]$(Spearman's $\rho=0.114, P=0.109$ ). Higher $C M D\left[K^{+}\right]$was associated with the presence of intracerebral hematoma on admission head computed tomography, CMD lactate/pyruvate ratio >40 and $C M D$ lactate $>4 \mathrm{mmol} / \mathrm{L}(P<0.05)$. In vitro retrodialysis data suggest that high $C M D\left[\mathrm{~K}^{+}\right]$was of brain cellular origin. Higher $C M D\left[K^{+}\right]$was significantly associated with poor 3-month outcome, even after adjusting for age and disease severity $(P<0.01)$.

Conclusions: The results of this pilot study suggest that brain extracellular [K'] may serve as a biomarker for brain tissue injury in poor-grade aSAH patients. Further studies are needed to elucidate the relevance of brain interstitial $\mathrm{K}^{+}$levels in the pathophysiology of secondary brain injury after aSAH.

\section{Introduction}

Maintenance of brain ion homeostasis is critical for synaptic transmission and proper functioning of the neuron-glia signalling network [1]. After aneurysmal subarachnoid hemorrhage $(\mathrm{aSAH})$, several mechanisms may contribute to transient or prolonged accumulation of brain extracellular potassium $\left(\mathrm{K}^{+}\right)$: erythrocytolysis [2], unspecific membrane breakdown due to parenchymal injury [3-5], dysfunction of $\mathrm{Na}^{+} / \mathrm{K}^{+}$pump [1,6-8] and, on the

\footnotetext{
* Correspondence: raimund.helbok@uki.at

${ }^{\dagger}$ Equal contributors

${ }^{1}$ Neurological Intensive Care Unit, Department of Neurology, Innsbruck Medical University, Innsbruck, Austria

Full list of author information is available at the end of the article
}

one hand, compromised glial buffering $[9,10]$, on the other hand, activation of neuronal ATP-sensitive, or G protein-dependent, calcium-sensitive $\mathrm{K}^{+}$channels due to energy failure $[11,12]$. During aSAH, both blood compounds $[3,13]$ and ischemia [14] may induce cortical spreading depolarization (CSD). CSD leads to a transient or sustained increase of brain extracellular $\mathrm{K}^{+}$concentration $\left(\left[\mathrm{K}^{+}\right]\right)$up to $60 \mathrm{mmol} / \mathrm{L}$, far beyond its physiological range [8]. Notably, ictal epileptic events and spreading depolarization are the only events in the brain during which extracellular $\left[\mathrm{K}^{+}\right]$reaches such high levels [12,14]. For comparison, during ictal epileptic events, extracellular $\left[\mathrm{K}^{+}\right]$increases from only 3 to $12 \mathrm{mmol} / \mathrm{L}[15]$.

In patients with severe traumatic brain injury (TBI), higher brain extracellular $\left[\mathrm{K}^{+}\right]$was correlated with

\section{Ciomed Central}


higher cerebral microdialysis (CMD) lactate and CMD glutamate levels, increased intracranial pressure (ICP) and poor functional outcome, thus supporting a relationship between higher brain extracellular $\left[\mathrm{K}^{+}\right]$and dysfunction and/or damage of the brain parenchyma [5]. Derangement of plasma $\left[\mathrm{K}^{+}\right]$is associated with muscle weakness and cardiac arrhythmia as well as, to a lesser degree, cerebral symptoms such as lethargy, irritability, confusion and coma. Neurological symptoms are more likely related to concomitant $\mathrm{Na}^{+}$and acidbase disturbances, suggesting that brain extracellular $\left[\mathrm{K}^{+}\right]$may be independent of plasma $\mathrm{K}^{+}$levels. The results of studies done in animal models have shown that the disrupted blood-brain barrier can be open to large molecules, but can maintain the stability of the extracellular $\left[\mathrm{K}^{+}\right]$[16]. Little is known about the relationship between plasma and cerebral extracellular $\left[\mathrm{K}^{+}\right]$ after acute brain injury in humans.

In this pilot study, we investigated the relationship between brain extracellular $\left[\mathrm{K}^{+}\right]$and plasma $\left[\mathrm{K}^{+}\right]$and the association of high $\mathrm{CMD}\left[\mathrm{K}^{+}\right]$with brain metabolic and hemodynamic parameters and functional outcome in poor-grade aSAH patients.

\section{Material and methods \\ Study population}

Data were recorded prospectively for 28 consecutive aSAH patients who underwent brain multimodal neuromonitoring, including ICP, brain tissue oxygen tension $\left(\mathrm{P}_{\mathrm{bt}} \mathrm{O}_{2}\right)$ and cerebral microdialysis, between September 2010 and October 2012, and the CMD samples were retrospectively analyzed for $\mathrm{CMD}\left[\mathrm{K}^{+}\right]$. The following institutional criteria for invasive neuromonitoring were applied: (1) Glasgow Coma Scale (GCS) score $\leq 8$ upon admission or deterioration to a GCS score $\leq 8$ during hospitalization, (2) low likelihood of regaining consciousness within the next 48 hours, (3) high likelihood of surviving at least 48 hours and (4) age $>=18$ years. The study was approved by the Independent Ethics Committee of Innsbruck Medical University (UN3898 285/4.8) and was carried out in adherence to the ethical conduct of clinical research involving critically ill patients issued by the Austrian Federal Office for Safety in Health Care. In line with this, if incapacity as a result of the critical illness precluded standard informed consent, deferred consent was required according to the Independent Ethics Committee approval. After regaining the ability to consent, patients were informed without delay and asked for their consent for further participation in the study. In the case of persistent incapacity, proxy consent was obtained according to Austrian law. Additionally, the public on the research site was informed about the study by notice on the bulletin board at the neurological ICU.

\section{General management}

Patient care was carried out in adherence to the guidelines of the American Heart Association for management of aSAH [17]. Hemodynamic and fluid management were targeted to achieve a cerebral perfusion pressure (CPP) $>70 \mathrm{mmHg}$. The target for intracranial pressure (ICP) was $<20 \mathrm{mmHg}$. Patients were treated to maintain euvolemia, normonatremia and normokalemia, depending on disease severity and left at the discretion of the attending neurintensivist.

\section{Cerebral microdialysate and plasma potassium measurements}

Three consecutive CMD samples were pooled to obtain $>40 \mu$ l for analysis of $\mathrm{CMD}\left[\mathrm{K}^{+}\right]$using the i-STAT system and i-STAT EC8+ cartridges (Abbott Point of Care, Princeton, NJ, USA) [18]. Plasma electrolytes were measured using the ABL800 FLEX blood gas analyzer (Radiometer Medical, Brønshøj, Denmark).

\section{Monitoring and data acquisition}

Neuromonitoring probes were placed, through a subcutaneous tunnel or using a triple-lumen bolt, into the white matter at greatest risk for secondary brain injury, which we defined as brain tissue with the highest probability for damage due to delayed cerebral infarction. The location of the microdialysis catheter was confirmed by head CT scan, usually obtained within 24 hours after surgery, and graded to distinguish radiologically "normal" from "perilesional" tissue (CMD probe $<1 \mathrm{~cm}$ distant from a hematoma or hypodensity) or "intralesional" tissue (within a hemorrhagic or ischemic lesion). CMD was performed using a $100 \mathrm{kDa}$ cutoff microdialysis catheter (CMA-71; M Dialysis, Stockholm, Sweden), and perfusion fluid $\left(\mathrm{Na}^{+} 147 \mathrm{mmol} / \mathrm{L}, \mathrm{CaCl}^{2+} 1.2 \mathrm{mmol} / \mathrm{L}, \mathrm{MgCl}^{2+}\right.$ $0.9 \mathrm{mmol} / \mathrm{L}, \mathrm{KCl}^{+} 2.7 \mathrm{mmol} / \mathrm{L}$ (CNS perfusion fluid); $\mathrm{M}$ Dialysis) was pumped at a flow rate of $0.3 \mu \mathrm{l} / \mathrm{min}$. Hourly samples were analyzed (CMA 600 and ISCUS flex, $M$ Dialysis AB, Stockholm, Sweden) for interstitial glucose, pyruvate, lactate and glutamate concentrations and frozen at $-80^{\circ} \mathrm{C}$. ICP was measured with an intraparenchymal probe (NEUROVENT; RAUMEDIC, Helmbrechts, Germany), and $\mathrm{P}_{\mathrm{bt}} \mathrm{O}_{2}$ was measured using a Clark-type probe (LICOX; Integra LifeSciences, Plainsboro, NJ, USA). In weekly meetings of the study team (RH, BP, RB, MF, AS and ES), disease and treatment complications were evaluated as part of the development of an ongoing prospective database. Delayed cerebral infarction was defined as a newly appearing infarction found on follow-up brain CT scans and judged by an independent radiologist to be attributable to vasospasm. Pneumonia was defined as chest X-ray infiltrate plus elevated systemic inflammatory parameters. Survival and functional outcome were evaluated prospectively with the modified Rankin Scale 
(mRS) 3 months after aSAH by telephone interview conducted by a study nurse blinded to neuromonitoring data. Poor neurological outcome was defined as mRS score $>4$ (severe disability or death). An electronic patient data management system (Centricity Clinical Notification System with Centricity Critical Care 7.0 software; GE Healthcare, Little Chalfont, UK) was used to acquire digital data for blood pressure, ICP, CPP and $\mathrm{P}_{\mathrm{bt}} \mathrm{O}_{2}$ every 3 minutes from the monitoring device (CARESCAPE Monitor B650; GE Healthcare). Brain tissue hypoxia was defined as $\mathrm{P}_{\mathrm{bt}} \mathrm{O}_{2}<20 \mathrm{mmHg}$, based on previous studies demonstrating a higher risk of metabolic distress and poor outcome below this threshold value [19,20]. Low CPP was considered $\leq 70 \mathrm{mmHg}$ in accordance with data showing an association of this threshold with metabolic crisis (CMD lactate/pyruvate ratio (LPR) $>40$ and CMD glucose $<0.7 \mathrm{mmol} / \mathrm{L}$ ) and brain tissue hypoxia [19]. Metabolic distress was defined as CMD LPR $>40$. We also categorized data for CMD LPR $>25$, deeming it an early warning sign of metabolic distress [21,22]. High CMD lactate, high CMD glutamate and low CMD pyruvate were considered to be present when measurements $>4 \mathrm{mmol} / \mathrm{L}[20,21],>10 \mu \mathrm{mol} / \mathrm{L}$ [22] and $<119 \mu \mathrm{mol} / \mathrm{L}$ $[20,23]$, respectively, were observed.

\section{Statistical analysis}

Data for CPP, ICP, $\mathrm{P}_{b t} \mathrm{O}_{2}$, plasma $\left[\mathrm{K}^{+}\right]$and CMD metabolites were time-matched to the 3-hour period of the pooled sample and averaged to the corresponding CMD $\left[\mathrm{K}^{+}\right]$analysis. Continuous variables were dichotomized based on clinical cutoff points or median values. Univariate and multivariate comparisons of pooled data were performed using a generalized linear model with a binomial distribution and logit link function. The model was extended by using generalized estimating equations with the autoregressive matrix of the first order to handle repeated observations of the same patient [24].

The percentage of CMD samples with $\mathrm{CMD}\left[\mathrm{K}^{+}\right]$above the median was calculated for each patient, to assess differences between outcome groups (Mann-Whitney $U$ test). For correlation analyses, Spearman's $\rho$ was used. The results are reported as medians with IQRs unless otherwise specified. $P<0.05$ was considered statistically significant. SPSS 21 software (SPSS Inc, Chicago, IL, USA) was used for data analysis.

\section{In vitro potassium measurements}

In vitro analysis was performed using a $100 \mathrm{kDa}$ cutoff CMD catheter (CMA-71) at a constant flow rate of $0.3 \mu \mathrm{l} / \mathrm{min}$ to determine the relative recovery rate. The relative recovery rate was defined as the $\left[\mathrm{K}^{+}\right]$level in the microdialysate divided by $\left[\mathrm{K}^{+}\right]$in three different $\mathrm{K}^{+}$dilutions (low, medium and high). The $\mathrm{K}^{+}$dilution was created using concentrated $\mathrm{K}^{+}\left(1 \mathrm{mmol} / \mathrm{ml} \mathrm{K}^{+}\right)$diluted by isotonic $\mathrm{NaCl}$ to obtain low $(2.2 \mathrm{mmol} / \mathrm{L})$, medium $(4.3 \mathrm{mmol} / \mathrm{L})$ and high $(9.0 \mathrm{mmol} / \mathrm{L}) \mathrm{K}^{+}$dilutions. The tip of the CMD catheter was then inserted into the $\mathrm{K}^{+}$dilution. Microdialysate was collected hourly and pooled over the course of 3 hours for analysis using the method described above. $\left[\mathrm{K}^{+}\right]$in the microdialysate was $9.0 \pm 0 \mathrm{mmol} / \mathrm{L}$ (SD) in the high $\left[\mathrm{K}^{+}\right]$dilution, $4.2 \pm 0.07 \mathrm{mmol} / \mathrm{L}(\mathrm{SD})$ in the medium $\left[\mathrm{K}^{+}\right]$dilution and $2.0 \pm 0.14 \mathrm{mmol} / \mathrm{L}(\mathrm{SD})$ in the

Table 1 Patient characteristics $(N=28)^{a}$

\begin{tabular}{|c|c|}
\hline Clinical characteristics & Data \\
\hline Age (yr) & 56 (47 to 68$)$ \\
\hline Sex (female) & $16(57 \%)$ \\
\hline \multicolumn{2}{|l|}{ Admission $\mathrm{H} \& \mathrm{H}$ grade } \\
\hline 2 & $3(11 \%)$ \\
\hline 3 & $6(21 \%)$ \\
\hline 4 & $3(11 \%)$ \\
\hline 5 & $16(57 \%)$ \\
\hline Admission APACHE II score & 18 (14 to 21$)$ \\
\hline \multicolumn{2}{|l|}{ Admission radiological characteristics } \\
\hline \multicolumn{2}{|l|}{ Modified Fisher scale score } \\
\hline 1 & $3(11 \%)$ \\
\hline 2 & $3(11 \%)$ \\
\hline 3 & $10(35 \%)$ \\
\hline 4 & $12(43 \%)$ \\
\hline IVH sum score & $5(0$ to 9$)$ \\
\hline Intracerebral hematoma & $13(46 \%)$ \\
\hline Aneurysm size $>10 \mathrm{~mm}$ & $8(29 \%)$ \\
\hline Generalized cerebral edema & $11(39 \%)$ \\
\hline \multicolumn{2}{|l|}{ Surgical procedures/interventions } \\
\hline Clipping & $20(71 \%)$ \\
\hline Hydrocephalus requiring CSF diversion & $22(79 \%)$ \\
\hline Hyperosmolar therapy & $14(50 \%)$ \\
\hline \multicolumn{2}{|l|}{ Complications } \\
\hline Pneumonia & $21(75 \%)$ \\
\hline Delayed cerebral infarction & $6(21 \%)$ \\
\hline \multicolumn{2}{|l|}{ Outcome characteristics } \\
\hline Length of hospital stay (days) & 40 (27 to 50$)$ \\
\hline \multicolumn{2}{|l|}{ 3-month mRS score } \\
\hline 0 to 1 & $5(17.9 \%)$ \\
\hline 2 to 3 & $6(21.4 \%)$ \\
\hline 4 & $6(21.4 \%)$ \\
\hline 5 & $6(21.4 \%)$ \\
\hline 6 & 5 (17.9\%) \\
\hline
\end{tabular}

${ }^{\mathrm{a}}$ APACHE $\|$ = Acute Physiology and Chronic Health Evaluation II; CSF = Cerebrospinal fluid; $\mathrm{H} \& \mathrm{H}=$ Hunt and Hess; IVH = Intraventricular hemorrhage; $\mathrm{mRS}=$ modified Rankin Scale. Data shown are $n$ (\%) for categorical variables and median (IQR) for continuous variables. 
low $\left[\mathrm{K}^{+}\right]$dilution after repetitive analyses, revealing relative in vitro recovery rates of $100 \%$ in the presence of high $\left[\mathrm{K}^{+}\right], 98 \%$ in the presence of medium $\left[\mathrm{K}^{+}\right]$and $91 \%$ in the presence of low $\left[\mathrm{K}^{+}\right]$. In order to determine the accuracy of this method, we double-analyzed the same $\left[\mathrm{K}^{+}\right]$dilutions at 3 hours, 6 hours and 9 hours after the beginning of in vitro microdialysis, which revealed identical $\left[\mathrm{K}^{+}\right]$at all time points.

\section{Results}

\section{Study population}

Twenty-eight aSAH patients were included in our analysis (Table 1). Neuromonitoring was initiated on day 1 after ictus ( 1 to 2 days). The CMD catheter location was in radiologically normal tissue in 15 patients $(54 \%)$ and in perilesional tissue in 13 patients (46\%). Four patients died during hospitalization due to brain herniation $(n=2)$, mesenteric ischemia $(n=1)$ or septic shock $(n=1)$. One of these patients died during the neuromonitoring period on the tenth day after ictus.

\section{Cerebral microdialysate and plasma potassium concentrations}

Admission plasma $\left[\mathrm{K}^{+}\right]$was $3.7 \mathrm{mmol} / \mathrm{L}$ ( 3.4 to $4 \mathrm{mmol} / \mathrm{L}$ ) and increased only slightly during hospitalization to $3.9 \mathrm{mmol} / \mathrm{L}$ (3.7 to $4.1 \mathrm{mmol} / \mathrm{L})$. Median CMD $\left[\mathrm{K}^{+}\right]$ was $3 \mathrm{mmol} / \mathrm{L}(2.7$ to $3.2 \mathrm{mmol} / \mathrm{L})$. Plasma $\left[\mathrm{K}^{+}\right]$did not correlate with $\mathrm{CMD}\left[\mathrm{K}^{+}\right]$(Spearman's $\rho=0.114 ; P=0.109$ ) (Figure 1).

\section{Cerebral microdialysate, plasma potassium and brain homeostasis}

$\mathrm{CMD}\left[\mathrm{K}^{+}\right]$was positively correlated with $\mathrm{CMD}$ lactate levels (Spearman's $\rho 0.453 ; P<0.0001$ ), CMD LPR (Spearman's $\rho=$ $0.368 ; P<0.0001$ ) and CMD glutamate levels (Spearman's $\rho=$ $0.355 ; P=0.0002)$, whereas the strongest correlation was found during days 7 to 12 (CMD lactate: Spearman's $\rho=$ 0.489, $P<0.0001$; CMD LPR $\rho=0.006$; Spearman's $\rho=0.463$; CMD glutamate $\rho=0.000$; Spearman's $\rho=0.481$ ) and in patients with delayed cerebral infarction (CMD glutamate $\rho=$ 0.005; Spearman's $\rho=0.840, P<0.01$; CMD lactate $\rho=0.003$ Spearman's $\rho=0.773, P<0.01)$. Univariate analysis revealed an association between higher $\mathrm{CMD}\left[\mathrm{K}^{+}\right]$and CMD LPR $>25$, CMD LPR $>40$, CMD lactate $>4 \mathrm{mmol} / \mathrm{L}$, intraventricular hemorrhage (IVH) sum score $>5$ (median), presence of intracerebral hematoma (ICH) on admission head $\mathrm{CT}$ and perilesional probe location (Table 2). In the multivariate model, higher $\mathrm{CMD}\left[\mathrm{K}^{+}\right]$was significantly associated with CMD LPR $>25$, CMD LPR $>40$, CMD lactate $>4 \mathrm{mmol} / \mathrm{L}$ and presence of $\mathrm{ICH}$ after adjusting for probe location and CPP $\leq 70 \mathrm{mmHg}$ (Table 3 ).

There was no association between brain metabolic and physiological parameters and higher plasma $\left[\mathrm{K}^{+}\right]$(data not shown).

\section{Cerebral microdialysate potassium concentration, brain metabolism and outcome}

The percentage of episodes of higher CMD $\left[\mathrm{K}^{+}\right]$(above the median of $3 \mathrm{mmol} / \mathrm{L}$ ) was higher in patients with poor 3-month outcomes (71\% (50\% to $78 \%)$ ) compared to

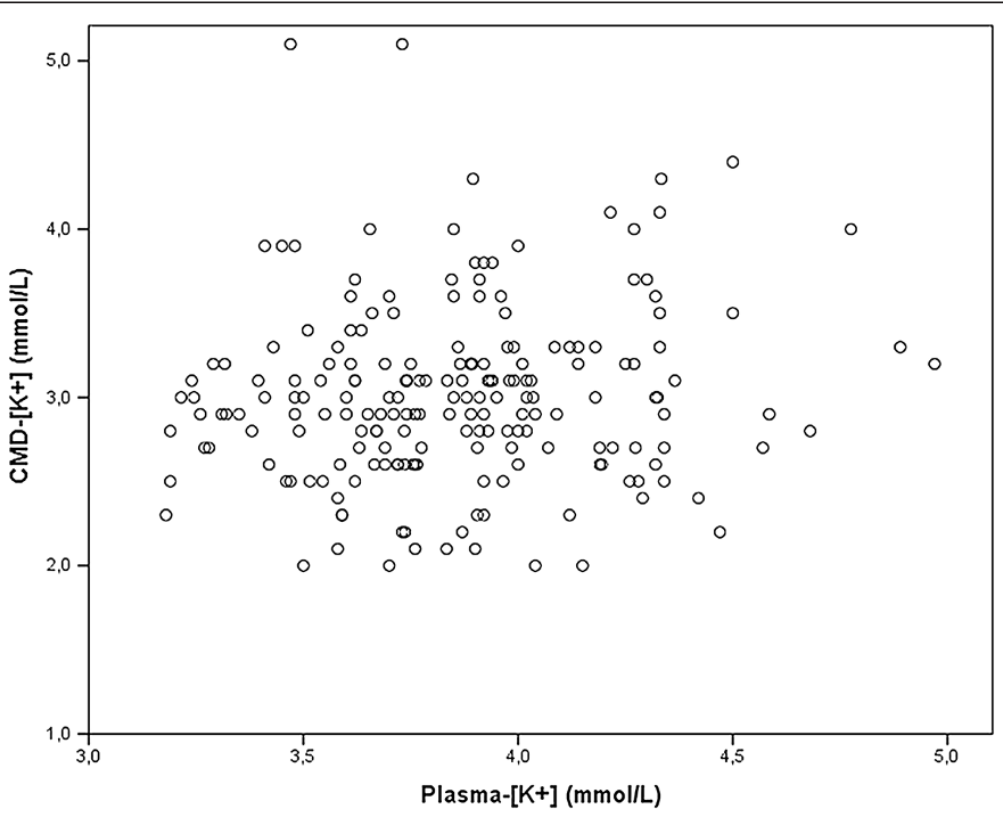

Figure 1 Correlation between potassium concentrations in plasma and cerebral microdialysate concentrations. $\left[K^{+}\right]=$Potassium concentration; $\mathrm{CMD}=$ Cerebral microdialysate. 
Table 2 Factors associated with higher potassium concentration in cerebral microdialysate ${ }^{a}$

\begin{tabular}{|c|c|c|}
\hline \multirow[b]{2}{*}{ Independent variables } & \multicolumn{2}{|c|}{$\mathrm{CMD}\left[\mathrm{K}^{+}\right]>3 \mathrm{mmol} / \mathrm{L}$} \\
\hline & OR $(95 \% \mathrm{Cl})$ & $P$-value \\
\hline Age $>56$ yr (median) & $0.7(0.3$ to 2.0$)$ & 0.548 \\
\hline Hunt and Hess grade $>3$ & $2.1(0.8$ to 5.5$)$ & 0.141 \\
\hline APACHE II score > 18 (median) & $1.6(0.6$ to 4.4$)$ & 0.322 \\
\hline Perilesional CMD probe location & $3.4(1.3$ to 8.9$)$ & 0.010 \\
\hline Modified Fisher scale $=4$ & $1.4(0.5$ to 3.8$)$ & 0.487 \\
\hline IVH sum score >5 (median) & $3.0(1.1$ to 8.1$)$ & 0.026 \\
\hline Intracerebral hematoma & $3.1(1.2$ to 8.1$)$ & 0.022 \\
\hline Bicaudate index $>0.2$ & $1.2(0.4$ to 3.4$)$ & 0.764 \\
\hline Admission GCE & $0.6(0.2$ to 1.9$)$ & 0.425 \\
\hline Delayed cerebral infarction & $1.4(0.4$ to 5.4$)$ & 0.623 \\
\hline $\mathrm{ICP}>20 \mathrm{mmHg}$ & 2.8 (1.0 to 8$)$ & 0.058 \\
\hline $\mathrm{CPP} \leq 70 \mathrm{mmHg}$ & $1.8(0.8$ to 3.8$)$ & 0.128 \\
\hline $\mathrm{P}_{\mathrm{bt}} \mathrm{O}_{2}<20 \mathrm{mmHg}$ & 1.7 (0.6 to 2.9$)$ & 0.422 \\
\hline CMD lactate $>4$ mmol/L & $4.2(2.0$ to 8.7$)$ & 0.0001 \\
\hline CMD pyruvate $<119 \mu \mathrm{mol} / \mathrm{L}$ & $0.7(0.3$ to 1.4$)$ & 0.267 \\
\hline CMD LPR $>25$ & 3.6 (1.4 to 9.2$)$ & 0.008 \\
\hline CMD LPR >40 & $5.1(2.5$ to 10.1$)$ & $<0.0001$ \\
\hline CMD glucose $<0.7 \mathrm{mmol} / \mathrm{L}$ & $0.9(0.5$ to 1.7$)$ & 0.719 \\
\hline CMD glutamate $>10 \mu \mathrm{mol} / \mathrm{L}$ & 2.1 (0.9 to 5.0$)$ & 0.099 \\
\hline
\end{tabular}

${ }^{a}$ APACHE II = Acute Physiology and Chronic Health Evaluation II; $\mathrm{Cl}=$ Confidence interval; $C M D=$ Cerebral microdialysate; $C P P=$ Cerebral perfusion pressure; $\mathrm{GCE}=$ Generalized cerebral edema; ICP = Intracranial pressure; IVH = Intraventricular hemorrhage; $\left[\mathrm{K}^{+}\right]=$potassium concentration; $\mathrm{LPR}=$ Lactate/pyruvate ratio; $\mathrm{OR}=$ Odds ratio; $\mathrm{Pbt}_{\mathrm{bt}} \mathrm{O}_{2}=$ Brain tissue oxygen tension. Higher $\mathrm{CMD}\left[\mathrm{K}^{+}\right]$was defined as values above the median.

patients with mRS scores $\leq 4(12.5 \%$ (0 to $56 \%))(P=0.006)$ (Figure 2). To verify the association between poor outcome and higher $\mathrm{CMD}\left[\mathrm{K}^{+}\right]$and CMD LPR $>40$, generalized estimation equation models were calculated with day after $\mathrm{SAH}$ as the factor and age and admission Hunt and Hess grade as the covariates. These adjusted models showed

Table 3 Multivariate model of factors associated with higher potassium concentration in cerebral microdialysate ${ }^{a}$

\begin{tabular}{lll}
\hline & \multicolumn{2}{c}{ CMD $\left[\mathbf{K}^{+}\right]>\mathbf{3} \mathbf{~ m m o l} / \mathbf{L}$} \\
\cline { 2 - 3 } Independent variables & OR $(\mathbf{9 5 \%} \mathbf{C l})$ & $\boldsymbol{P}$-values \\
\hline IVH sum score $>5$ (median) & $2.2(0.8$ to 6.2$)$ & 0.124 \\
Intracerebral hematoma & $3.3(1.3$ to 8.2$)$ & 0.013 \\
ICP $>20 \mathrm{mmHg}$ & $2.7(1.0$ to 7.3$)$ & 0.058 \\
CMD lactate $>4 \mathrm{mmol} / \mathrm{L}$ & $4.3(2.1$ to 8.7$)$ & $<0.0001$ \\
CMD LPR $>25$ & $5.2(1.8$ to 15.0$)$ & 0.002 \\
CMD LPR $>40$ & $4.4(2.2$ to 8.8$)$ & $<0.0001$ \\
\hline
\end{tabular}

${ }^{\mathrm{a}} \mathrm{Cl}=$ Confidence interval; $\mathrm{CMD}=$ Cerebral microdialysate; $\mathrm{ICP}=$ Intracranial pressure; IVH = Intraventricular hemorrhage; LPR = Lactate/pyruvate ratio; $\mathrm{OR}=$ Odds ratio. Each model was adjusted for probe location and cerebral perfusion pressure $\leq 70 \mathrm{mmHg}$. Higher $\mathrm{CMD}[\mathrm{K}+]$ was defined as value above the overall median.

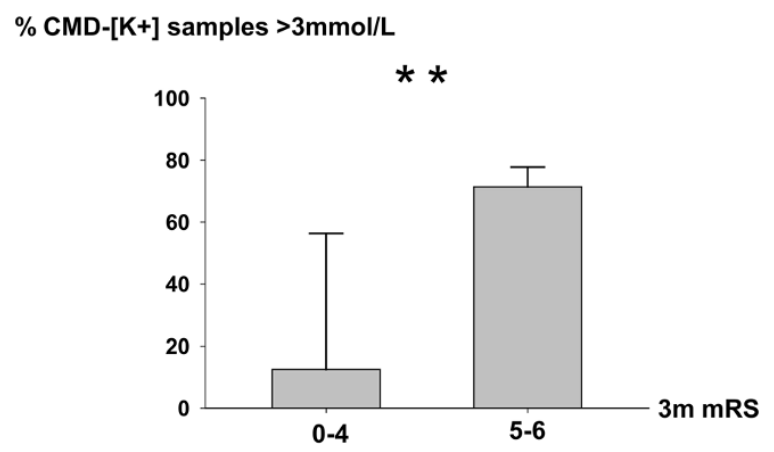

Figure 2 Potassium concentration in cerebral microdialysate depending on functional outcome. Percentage of episodes of potassium concentration $\left(\left[\mathrm{K}^{+}\right]\right)$above $3 \mathrm{mmol} / \mathrm{L}$ in cerebral microdialysate (CMD) between patients with modified Rankin Scale (mRS) scores $\leq 4$ and those with $m R S$ scores $>4$ three months after ictus. Bars represent median and IQR. ${ }^{*} P=0.006$.

a statistically significant effect of higher $\mathrm{CMD}\left[\mathrm{K}^{+}\right]$and CMD LPR $>40$ on poor functional 3-month outcomes $(P<0.01)$ (Figure 3$)$.

\section{Discussion}

The main findings of this study suggest that higher $\mathrm{CMD}\left[\mathrm{K}^{+}\right]$levels are associated with brain metabolic distress and poor functional outcomes and that $\mathrm{CMD}\left[\mathrm{K}^{+}\right]$ levels do not correlate with corresponding plasma $\left[\mathrm{K}^{+}\right]$ levels. The poor correlation between brain extracellular and plasma $\left[\mathrm{K}^{+}\right]$suggests integrity of the electrical barrier [16] and a primarily brain parenchymal origin of CMD $\left[\mathrm{K}^{+}\right]$. Brain extracellular $\mathrm{K}^{+}$accumulation in the subcortical brain regions may be explained secondarily to membrane breakdown [3-5] and erythrocytolysis [2] (Figure 4). In line with that explanation, we found higher $\mathrm{CMD}\left[\mathrm{K}^{+}\right]$in perilesional brain regions and an association with the presence of SAH related intraparenchymal hematoma. These findings suggest diffusion of extracellular $\mathrm{K}^{+}$through the interstitial spaces with $\left[\mathrm{K}^{+}\right]$gradient from intracerebral hematoma and infarction to adjacent and more distant brain areas. Furthermore, although not statistically significant, almost all episodes of ICP $>20 \mathrm{mmHg}$ had $\mathrm{CMD}\left[\mathrm{K}^{+}\right]$above the median, supporting the association between high $\mathrm{CMD}\left[\mathrm{K}^{+}\right]$and cell damage. In this study, we may have missed transient brain extracellular $\mathrm{K}^{+}$elevations because of our hourly sampling method, whereas a rapid-sampling microdialysis technique may detect rapid changes in brain extracellular $\left[\mathrm{K}^{+}\right][4]$.

Higher $\mathrm{CMD}\left[\mathrm{K}^{+}\right]$was associated with elevated CMD lactate levels and brain metabolic distress. This association may be explained by the phenomenon of inverse neurovascular coupling triggered by excessive extracellular $\left[\mathrm{K}^{+}\right]$, leading to vasoconstriction with consecutive regional hypoperfusion and metabolic derangement [25]. Moreover, excessive extracellular $\mathrm{K}^{+}$has been recognized 


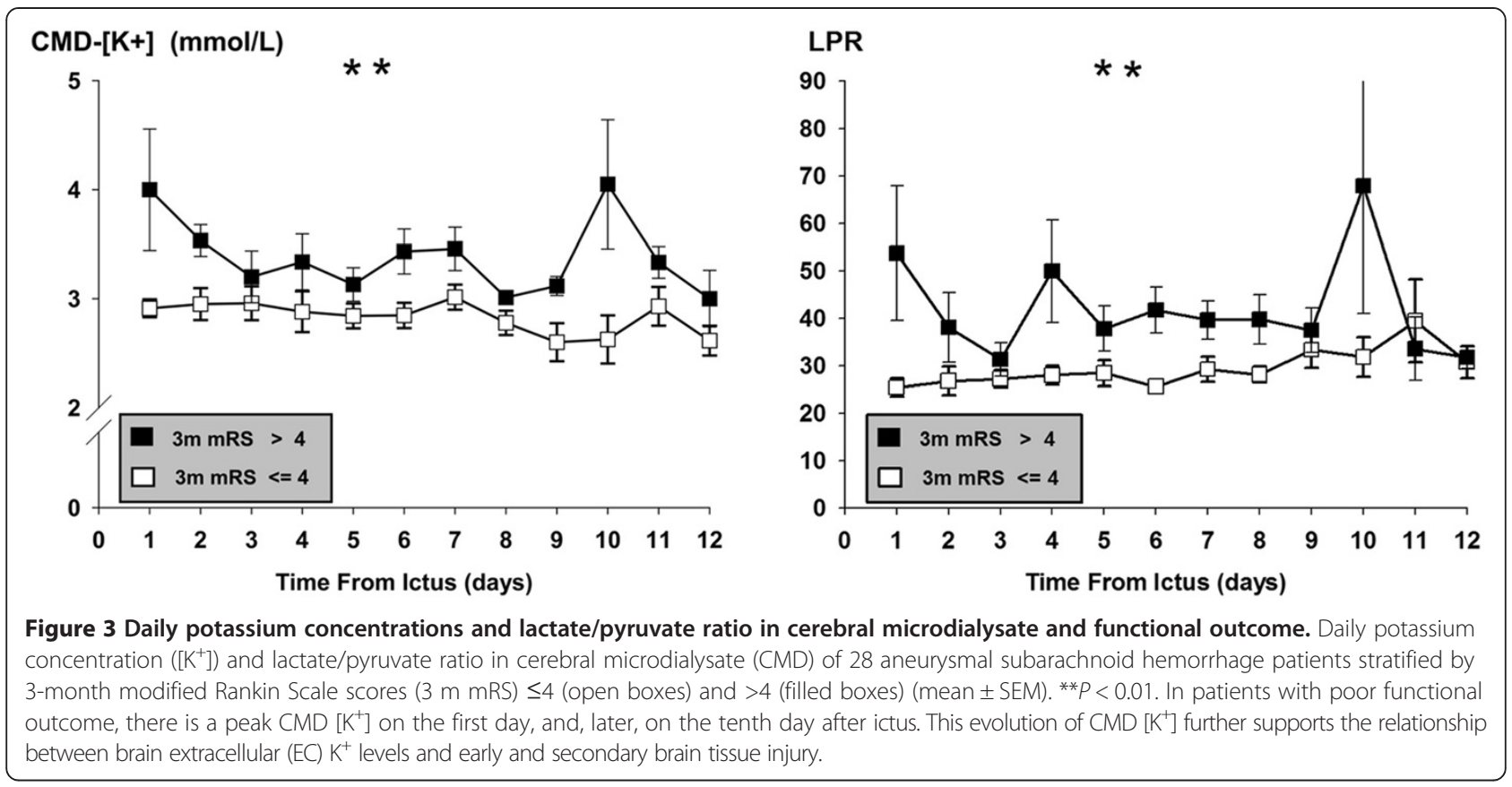

to play a pivotal role in the generation and propagation of cortical spreading depolarization (CSD) which, under a pathological environment, can lead to spreading ischemia [26-29]. Our study investigates $\mathrm{CMD}\left[\mathrm{K}^{+}\right]$and cerebral metabolism of the subcortical white matter. Spreading depolarization as a cortical phenomenon is highly energy-demanding and has been shown by previous researchers to cause neuronal dysfunction in subcortical areas of the brain in rodent models [12,30-32]. In patients with aSAH, there is growing evidence that CSDs occur abundantly [33]. Investigators in a recent clinical study demonstrated that clustered CSDs are associated with a

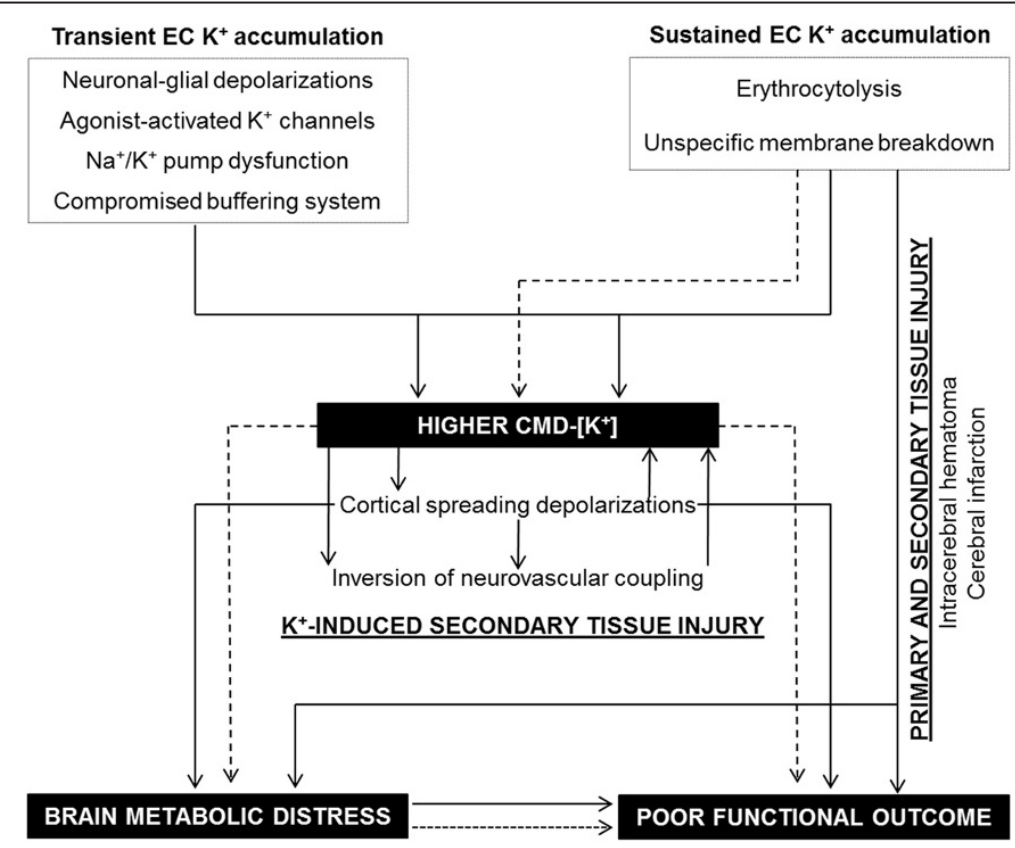

Figure 4 Interaction diagram between potential causes for and consequences of cerebral extracellular potassium accumulation. Interaction diagram between brain events that may lead to cerebral extracellular (EC) potassium accumulation and an explanation model for the relationship between higher cerebral microdialysate (CMD) $\mathrm{K}^{+}$concentration $\left[\mathrm{K}^{+}\right]$and cerebral metabolic distress and poor functional outcome, based on previously published literature (full line) and our findings (dashed line). For further description, see Discussion text. 
transient decrease in CMD glucose and an increase in CMD lactate and CMD LPR, which they measured by cerebral microdialysis [34] (Figure 4).

We found an independent association of both higher CMD $\left[\mathrm{K}^{+}\right]$and LPR with poor 3-month outcomes. Both parameters may be interpreted as surrogate markers for brain tissue injury after aSAH. According to this hypothesis, hemorrhage load and secondary brain injury are associated with disturbed brain metabolism and poor outcome [35-38] (Figure 4).

The potential toxic effect of $\mathrm{K}^{+}$load in aSAH patients raises an important issue for neuroprotective strategies that may embrace buffering or release of excessive extracellular $\mathrm{K}^{+}$. Clinical management can rest on avoiding further $\mathrm{K}^{+}$accumulation by maintaining balance between energy supply and demand in order to sustain the performance of the $\mathrm{Na}^{+} / \mathrm{K}^{+}$pump for neuronal repolarization $[39,40]$ and $\mathrm{K}^{+}$clearance by glial cells [41].

Our study has several important limitations. (1) Only poor-grade aSAH patients observed at a single center are represented in this study. This may have introduced a selection bias restricting the generalizability of our data to the whole aSAH patient population. (2) No causative association between higher $\mathrm{CMD}\left[\mathrm{K}^{+}\right]$and brain metabolism and patient outcome can be made on the basis of observational data. This study should be considered a pilot study conducted essentially to further elucidate pathophysiological mechanisms of secondary brain injury in patients with aSAH and to generate hypotheses based on our findings. (3) The low time resolution of $\mathrm{K}^{+}$measurements in our study may have introduced a washout effect, which causes underestimation of peak $\left[\mathrm{K}^{+}\right]$. The perfusion fluid used for cerebral microdialysis contained $\mathrm{K}^{+}$in its composition. Nevertheless, the high recovery rate for $\mathrm{K}^{+}$found in the in vitro analysis suggested free diffusion of $\mathrm{K}^{+}$with little obvious influence of the perfusion fluid $\mathrm{K}^{+}$. Therefore, $\mathrm{CMD}\left[\mathrm{K}^{+}\right]$may be interpreted as an approximation of real $\left[\mathrm{K}^{+}\right]$of the brain extracellular space. (4) Our approach of taking samples daily for measurement cannot be used to assess the dynamics between brain ionic, metabolic and physiological homeostasis and simply focus on transversal relationships between these parameters.

Despite our study's limitations, it addresses the association between brain extracellular $\left[\mathrm{K}^{+}\right]$with its systemic correlate and brain homeostasis in poor-grade aSAH patients. Moreover, our method proved to be feasible for bedside analysis of $\mathrm{K}^{+}$in the severely injured brain. Future development and implementation of CMD point-of-care analytical methods seems to be necessary for a complete understanding pathophysiologic mechanisms of secondary brain injury after human aSAH.

\section{Conclusions}

The findings of our pilot study suggest that higher CMD $\left[\mathrm{K}^{+}\right]$can be measured and may serve as a surrogate marker for brain injury in poor-grade aSAH patients. Further studies are needed to elucidate the relevance of interstitial $\mathrm{K}^{+}$levels in the pathophysiology of secondary brain injury after aSAH.

\section{Key messages}

- Higher $\mathrm{K}^{+}$levels in the extracellular space of the subcortical white matter may serve as a biomarker for brain tissue injury in poor-grade aneurysmal subarachnoid hemorrhage patients.

- Work done in experimental models suggests that elevated $\mathrm{K}^{+}$levels in the extracellular space can drive secondary brain injury after a subarachnoid hemorrhage. Further human studies are needed to confirm this hypothesis.

\section{Abbreviations}

aSAH: Aneurysmal subarachnoid hemorrhage; CMD: Cerebral microdialysis; CPP: Cerebral perfusion pressure; CSD: Cortical spreading depolarization; CT: Computed tomography; GCS: Glasgow Coma Scale; ICP: Intracranial pressure; $\mathrm{K}^{+}$: Potassium; $\left[\mathrm{K}^{+}\right]$: Potassium concentration; LPR: Lactate/pyruvate ratio; mRS: Modified Rankin scale; $\mathrm{P}_{\mathrm{bt}} \mathrm{O}_{2}$ : Brain tissue oxygen tension.

\section{Competing interests}

The authors declare that they have no competing interests.

\section{Authors' contributions}

APA and AJS were involved in the acquisition of data, statistical analysis, interpretation of data, study design and manuscript drafting. $\mathrm{RH}$ was involved in the study design, interpretation of data, statistical analysis, manuscript drafting and final revision of the manuscript. $R B, B P, M F, A D, P L$ and ES participated in the acquisition and interpretation of data and in the final revision of the manuscript. FS and CT were involved in the study design and data acquisition and interpretation of the data. $\mathrm{WOH}$ and JPN were involved in the study design, data processing and statistical analysis. All authors read, critically reviewed and approved the final manuscript.

\section{Acknowledgements}

APA was supported by the Department to Department Co-operation Programme of the European Federation of Neurological Societies. RH and AS are supported by a grant from the Austrian National Bank (OeNB 14082), Innsbruck Medical University and Alzheimer Austria.

\section{Author details}

'Neurological Intensive Care Unit, Department of Neurology, Innsbruck Medical University, Innsbruck, Austria. ${ }^{2}$ Department of Neurosciences, North Lisbon Hospital Centre, Santa Maria Hospital, Lisbon, Portugal. ${ }^{3}$ Department of Neurosurgery, Innsbruck Medical University, Innsbruck, Austria. Institute of Biomedical Informatics, UMIT-University for Health Sciences, Medical Informatics and Technology, Eduard Wallnoefer-Zentrum 1, 6060 Hall, Austria.

Received: 1 February 2014 Accepted: 21 May 2014

Published: 11 June 2014

\section{References}

1. Hansen AJ: Effect of anoxia on ion distribution in the brain. Physiol Rev 1985, 65:101-148.

2. Ohta OOK, Siguma M, Yamamoto M, Shimizu K, Toda N: Cerebral vasospasm following ruptured intracranial aneurysms, especially some contributions of potassium ion released from subarachnoid hematoma to delayed cerebral vasospasm. In Vascular Neuroeffector Mechanisms: 4th International Symposium. Edited by Bevan JA. New York: Raven; 1983:353-358.

3. Hubschmann OR, Kornhauser D: Effects of intraparenchymal hemorrhage on extracellular cortical potassium in experimental head trauma. I Neurosurg 1983, 59:289-293. 
4. Katayama Y, Becker DP, Tamura T, Hovda DA: Massive increases in extracellular potassium and the indiscriminate release of glutamate following concussive brain injury. J Neurosurg 1990, 73:889-900.

5. Reinert M, Khaldi A, Zauner A, Doppenberg E, Choi S, Bullock R: High extracellular potassium and its correlates after severe head injury: relationship to high intracranial pressure. Neurosurg Focus 2000, 8:e10.

6. Müller M, Somjen GG: $\mathrm{Na}^{+}$dependence and the role of glutamate receptors and $\mathrm{Na}^{+}$channels in ion fluxes during hypoxia of rat hippocampal slices. J Neurophysiol 2000, 84:1869-1880.

7. Leresche N, Parri HR, Erdemli G, Guyon A, Turner JP, Williams SR, Asprodini E, Crunelli V: On the action of the anti-absence drug ethosuximide in the rat and cat thalamus. J Neurosci 1998, 18:4842-4853.

8. Hansen AJ, Zeuthen T: Extracellular ion concentrations during spreading depression and ischemia in the rat brain cortex. Acta Physiol Scand 1981, 113:437-445.

9. Largo C, Ibarz JM, Herreras O: Effects of the gliotoxin fluorocitrate on spreading depression and glial membrane potential in rat brain in situ. J Neurophysiol 1997, 78:295-307.

10. Lian $X Y$, Stringer $\mathrm{J}$ : Astrocytes contribute to regulation of extracellular calcium and potassium in the rat cerebral cortex during spreading depression. Brain Res 2004, 1012:177-184.

11. Erdemli G, Xu YZ, Krnjević K: Potassium conductance causing hyperpolarization of CA1 hippocampal neurons during hypoxia. J Neurophysiol 1998 80:2378-2390

12. Müller $\mathrm{M}$, Somjen GG: $\mathrm{Na}^{+}$and $\mathrm{K}^{+}$concentrations, extra- and intracellular voltages, and the effect of TTX in hypoxic rat hippocampal slices. J Neurophysiol 2000, 83:735-745.

13. Hubschmann OR, Kornhauser D: Effect of subarachnoid hemorrhage on the extracellular microenvironment. J Neurosurg 1982, 56:216-221.

14. Nedergaard M, Hansen AJ: Characterization of cortical depolarizations evoked in focal cerebral ischemia. J Cereb Blood Flow Metab 1993, 13:568-574.

15. Heinemann U, Lux HD: Ceiling of stimulus induced rises in extracellular potassium concentration in the cerebral cortex of cat. Brain Res 1977, 120:231-249.

16. Kang EJ, Major S, Jorks D, Reiffurth C, Offenhauser N, Friedman A, Dreier JP: Blood-brain barrier opening to large molecules does not imply blood-brain barrier opening to small ions. Neurobiol Dis 2013, 52:204-218.

17. Connolly ES Jr, Rabinstein AA, Carhuapoma JR, Derdeyn CP, Dion J, Higashida RT, Hoh BL, Kirkness CJ, Naidech AM, Ogilvy CS, Patel AB, Thompson BG, Vespa P, American Heart Association Stroke Council, Council on Cardiovascular Radiology and Intervention, Council on Cardiovascular Nursing, Council on Cardiovascular Surgery and Anesthesia, Council on Clinical Cardiology: Guidelines for the management of aneurysmal subarachnoid hemorrhage: a guideline for healthcare professionals from the American Heart Association/American Stroke Association. Stroke 2012, 43:1711-1737.

18. Veldhoen ES, de Vooght KM, Slieker MG, Versluys AB, Turner NM: Analysis of bloodgas, electrolytes and glucose from intraosseous samples using an i-STAT point-of-care analyser. Resuscitation 2013, 85:359-363.

19. Schmidt JM, Ko SB, Helbok R, Kurtz P, Stuart RM, Presciutti M, Fernandez L, Lee K, Badjatia N, Connolly ES, Claassen J, Mayer SA: Cerebral perfusion pressure thresholds for brain tissue hypoxia and metabolic crisis after poor-grade subarachnoid hemorrhage. Stroke 2011, 42:1351-1356.

20. Oddo M, Levine JM, Frangos S, Maloney-Wilensky E, Carrera E, Daniel RT, Levivier M, Magistretti PJ, LeRoux PD: Brain lactate metabolism in humans with subarachnoid hemorrhage. Stroke 2012, 43:1418-1421.

21. Timofeev I, Carpenter KL, Nortje J, Al-Rawi PG, O'Connell MT, Czosnyka M, Smielewski P, Pickard JD, Menon DK, Kirkpatrick PJ, Gupta AK, Hutchinson PJ: Cerebral extracellular chemistry and outcome following traumatic brain injury: a microdialysis study of 223 patients. Brain 2011, 134:484-494.

22. Reinstrup P, Ståhl N, Mellergård P, Uski T, Ungerstedt U, Nordström CH: Intracerebral microdialysis in clinical practice: baseline values for chemical markers during wakefulness, anesthesia, and neurosurgery. Neurosurgery 2000, 47:701-710.

23. Samuelsson C, Hillered L, Zetterling M, Enblad P, Hesselager G, Ryttlefors $M$, Kumlien E, Lewén A, Marklund N, Nilsson P, Salci K, Ronne-Engström E: Cerebral glutamine and glutamate levels in relation to compromised energy metabolism: a microdialysis study in subarachnoid hemorrhage patients. J Cereb Blood Flow Metab 2007, 27:1309-1317.

24. Zeger SL, Liang KY: Longitudinal data analysis for discrete and continuous outcomes. Biometrics 1986, 42:121-130.
25. Koide M, Bonev AD, Nelson MT, Wellman GC: Inversion of neurovascular coupling by subarachnoid blood depends on large-conductance $\mathrm{Ca}^{2+}$-activated $\mathrm{K}^{+}$ (BK) channels. Proc Natl Acad Sci U S A 2012, 109:E1387-E1395.

26. Grafstein B: Mechanism of spreading cortical depression. J Neurophysio 1956, 19:154-171.

27. Obrenovitch TP, Zilkha E: High extracellular potassium, and not extracellular glutamate, is required for the propagation of spreading depression. J Neurophysiol 1995, 73:2107-2114.

28. Dreier JP, Körner K, Ebert N, Görner A, Rubin I, Back T, Lindauer U, Wolf T, Villringer A, Einhäupl KM, Lauritzen M, Dirnagl U: Nitric oxide scavenging by hemoglobin or nitric oxide synthase inhibition by $\mathrm{N}$-nitro-L-arginine induces cortical spreading ischemia when $\mathrm{K}^{+}$is increased in the subarachnoid space. J Cereb Blood Flow Metab 1998, 18:978-990.

29. Dreier JP, Ebert N, Priller J, Megow D, Lindauer U, Klee R, Reuter U, Imai Y, Einhäupl KM, Victorov I, Dirnagl U: Products of hemolysis in the subarachnoid space inducing spreading ischemia in the cortex and focal necrosis in rats: a model for delayed ischemic neurological deficits after subarachnoid hemorrhage? J Neurosurg 2000, 93:658-666.

30. Lendon $\mathrm{CL}$, Han BH, Salimi K, Fagan AM, Behrens MI, Muller MC, Holtzman DM: No effect of apolipoprotein $E$ on neuronal cell death due to excitotoxic and apoptotic agents in vitro and neonatal hypoxic ischaemia in vivo. Eur J Neurosci 2000, 12:2235-2242.

31. Müller M: Effects of chloride transport inhibition and chloride substitution on neuron function and on hypoxic spreading-depression-like depolarization in rat hippocampal slices. Neuroscience 2000, 97:33-45.

32. Siemkowicz E, Hansen AJ: Brain extracellular ion composition and EEG activity following 10 minutes ischemia in normo- and hyperglycemic rats. Stroke 1981, 12:236-240

33. Dreier JP: The role of spreading depression, spreading depolarization and spreading ischemia in neurological disease. Nat Med 2011, 17:439-447.

34. Sakowitz OW, Santos E, Nagel A, Krajewski KL, Hertle DN, Vajkoczy P, Dreier JP, Unterberg AW, Sarrafzadeh AS: Clusters of spreading depolarizations are associated with disturbed cerebral metabolism in patients with aneurysmal subarachnoid hemorrhage. Stroke 2013, 44:220-223.

35. Helbok R, Kurtz P, Vibbert M, Schmidt MJ, Fernandez L, Lantigua H, Ostapkovich ND, Connolly SE, Lee K, Claassen J, Mayer SA, Badjatia N: Early neurological deterioration after subarachnoid haemorrhage: risk factors and impact on outcome. J Neurol Neurosurg Psychiatry 2013, 84:266-270.

36. Sarrafzadeh A, Haux D, Küchler I, Lanksch WR, Unterberg AW: Poor-grade aneurysmal subarachnoid hemorrhage: relationship of cerebral metabolism to outcome. J Neurosurg 2004, 100:400-406

37. Sarrafzadeh A, Haux D, Sakowitz O, Benndorf G, Herzog H, Kuechler I, Unterberg A: Acute focal neurological deficits in aneurysmal subarachnoid hemorrhage: relation of clinical course, CT findings, and metabolite abnormalities monitored with bedside microdialysis. Stroke 2003, 34:1382-1388.

38. Schmidt JM, Wartenberg KE, Fernandez A, Claassen J, Rincon F, Ostapkovich ND, Badjatia N, Parra A, Connolly ES, Mayer SA: Frequency and clinical impact of asymptomatic cerebral infarction due to vasospasm after subarachnoid hemorrhage. J Neurosurg 2008, 109:1052-1059.

39. Lauritzen M, Dreier JP, Fabricius M, Hartings JA, Graf R, Strong AJ: Clinical relevance of cortical spreading depression in neurological disorders: migraine, malignant stroke, subarachnoid and intracranial hemorrhage, and traumatic brain injury. J Cereb Blood Flow Metab 2011, 31:17-35.

40. Somjen GG: Mechanisms of spreading depression and hypoxic spreading depression-like depolarization. Physiol Rev 2001, 81:1065-1096.

41. Macaulay N, Zeuthen T: Glial $\mathrm{K}^{+}$clearance and cell swelling: key roles for cotransporters and pumps. Neurochem Res 2012, 37:2299-2309.

doi:10.1186/cc13916

Cite this article as: Antunes et al:: Higher brain extracellular potassium is associated with brain metabolic distress and poor outcome after aneurysmal subarachnoid hemorrhage. Critical Care 2014 18:R119. 